\title{
Effect of Individual Innovativeness and Digital Literacy in Adopting the Nursing Care Plan Mobile/Web Application Developed
}

\author{
Semra Eyi, BSN, MSc, $P h D^{1^{*}}$, Tülay Demiralay, MSc, $P h D^{2}$ and Erdem Öngün, $M S c, P h D^{3}$ \\ ${ }^{1}$ Department of Surgical Nursing, Faculty of Health Sciences, Eskişehir Osmangazi University, Odunpazari, Eskişehir, Turkey \\ ${ }^{2}$ Banking and Insurance Department, Keşan Yusuf Çapraz School of Applied Sciences, Trakya University, Edirne, Turkey \\ ${ }^{3}$ Public Relations and Advertising Department, Keşan Yusuf Çapraz School of Applied Sciences, Trakya University, Edirne, \\ Turkey
}

*Corresponding author: Dr. Semra Eyi, Assistant Professor, BSN, MSc, Ph.D., Department of Surgical Nursing, Faculty of Health Sciences, Eskişehir Osmangazi University, Odunpazari, Eskişehir, Turkey, Tel: +90-5426955337

\begin{abstract}
Background: The Covid-19 pandemic showed especially the importance of nursing students' education with digital literacy. The aim of this research work was to study the effect of individual innovativeness and digital literacy on the adoption of mobile/web application in nursing care plan developed for nursing students as a result of nursing care plan standardization process and expansion of its usage.

Methods: The study consists of 200 students in clinical trainings. Data were collected using individual innovation scale, digital literacy scale and Likert type questionnaire. The data were evaluated SPSS 21.0 package and path analysis by creating separate models on AMOS 21.0 package.

Results: Students "individual innovation" level increases significantly do their digital literacy level. Improvement in digital literacy makes it possible for students to assess the mobile/web application as easier and more comprehensible. The increase in digital literacy through the effect of individual innovation bears positive effect on the assessment that students find it more advantageous to prepare their nursing care plans through mobile/web application.

Conclusion: Develop their individual innovation and direct them to work with mobile technologies in both clinical setting and throughout their nursing education, improving the level of nursing students' digital literacy plays a very important role.
\end{abstract}

\section{Keywords}

Nursing care plan, Nursing process, Nursing communication and informatics, Mobile application, Automation system

\section{Introduction}

The development in information technologies (ITs), widespread use of mobile devices has considerably influenced nursing applications and also made it possible to reach clinical decisions [1]. In addition, the mobile technology integrated into the clinical routine has significantly improved the communication process, removed unnecessary documentation in the related process and finally increased patient quality in the long term.

Although mobile technologies have been recently introduced to nursing education programs, they have been exploited more and more as they facilitate recalling numerous variables of human health and supporting information management and clinical trainings [2].

International Council of Nurses state that parallel to technological developments, nursing profession is to innovate itself. The Council underlined that nurses are supposed to take the responsibility of a more qualified and cost-efficient nursing care [3]. They need to be innovative and initiate innovation. Following the emphasis put by the Council, individual innovativeness (II) has become a term to be described as a new approach, work style and technological assistance through which new ideas and individual acceptance are appreciated [4]. It is stated that although innovative practices in

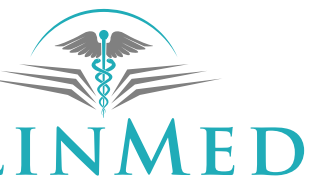

INTERNATIONAL LIBRARY

Citation: Eyi S, Demiralay T, Öngün E (2022) Effect of Individual Innovativeness and Digital Literacy in Adopting the Nursing Care Plan Mobile/Web Application Developed. Int Arch Nurs Health Care 8:170. doi.org/10.23937/2469-5823/1510170

Accepted: January 21, 2022: Published: January 23, 2022

Copyright: @ 2022 Eyi S, et al. This is an open-access article distributed under the terms of the Creative Commons Attribution License, which permits unrestricted use, distribution, and reproduction in any medium, provided the original author and source are credited. 
nursing have contributed a lot to individuals and public health development, they still do not appear to be recognized enough by nurses. As a solution, activities related to the development of digital literacy (DL) need to be promoted so that individuals starting from their early school years can develop appropriate awareness and attitudes to define access and appropriate use of digital sources. Developing digital literacy in nursing education supports the evidence-based on applications by providing access to the use of knowledge and information [5]. It is often emphasized in the literature that studies towards providing easier access to mobile devices by students, promoting their level digital literacy and individual innovation and collaboration with mobile technologies in both clinical settings and nursing education need to be conducted.

\section{Objectives}

The study aims at researching the effect of individual innovation level and digital literacy level on the adoption of the nursing care plan mobile/web (MW) application developed for nursing students as a result of nursing care plan standardization process and expansion of its usage.

\section{Material/Subjects/Patients and Methods}

\section{Design}

This study is a descriptive, cross-sectional type study.

\section{Sample}

The universe of the research is made up of a total of 200 students that participate in the clinical training practice in a university hospital. The minimum number of participants required for the study was determined as 197 using power analysis software G-power 3.9.1 $(\mathrm{n}=$ $197, \alpha=0.05,1-\beta=0.80$ ).

\section{Data Collection}

\section{Step 1}

A format of nursing care plan for students was developed and evaluated by experts and necessary revisions/corrections were made. The algorithm of the nursing care plan automation system was designed by student trainers in an excel format, later converted into a web application. The web application was piloted by ten students and based on the feedback from the piloting, the algorithm of the nursing care plan automation system was revised. Nursing care plan automation system is based on Php server-side scripting language with MySQL database and HTML5 tags. Tablet and MW conformity of the system was given priority. The homepage of the nursing care plan automation system includes informative content, which also enables member students to choose their supervisors and log in. After the nursing care plan automation system was completed by the hired software company, the software was ready to be used in clinical training by students in the following semester (Figure 1).

\section{Step 2}

The data of the study were collected by a Likerttype questionnaire developed by the researchers of the

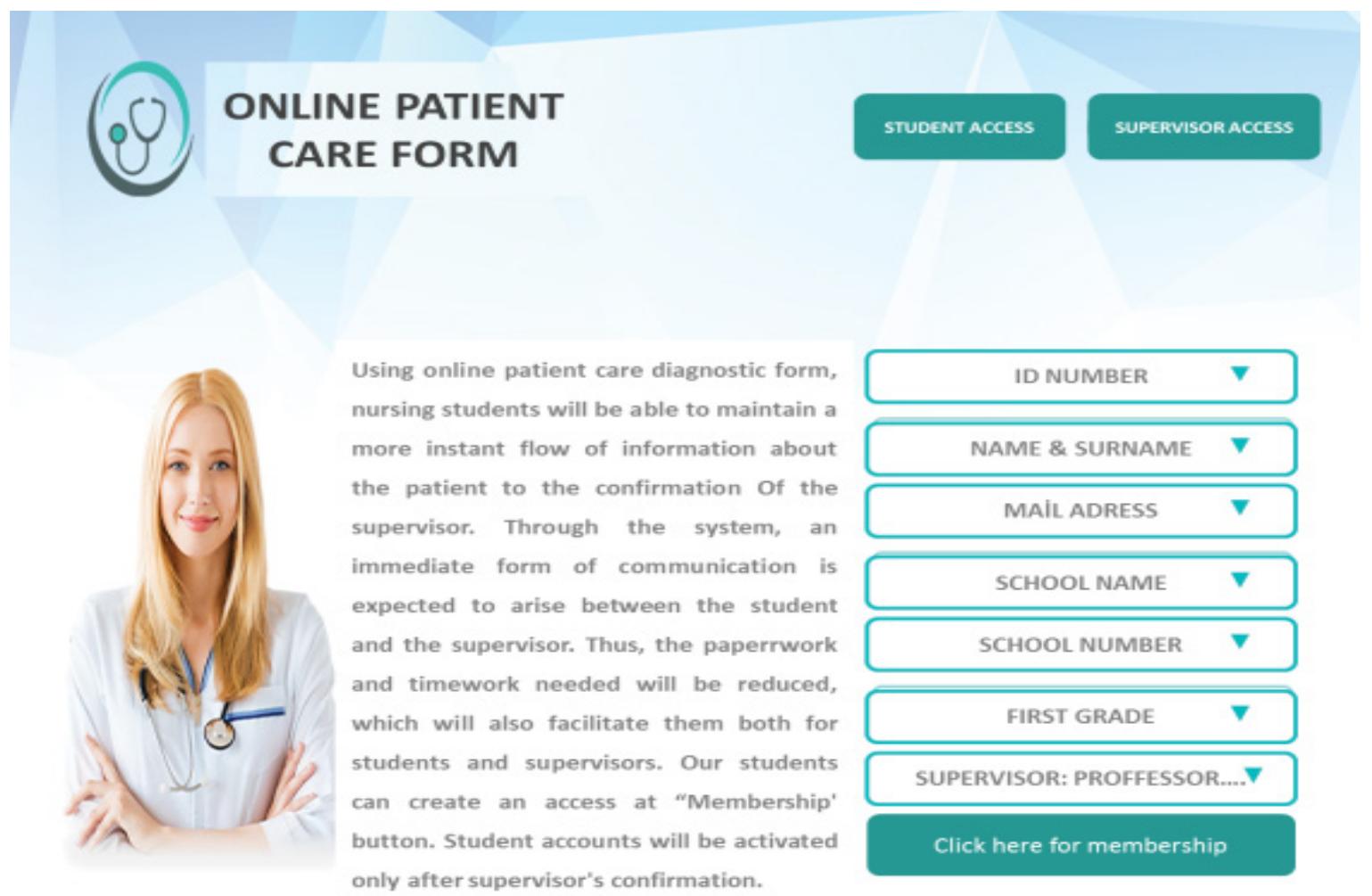

Figure 1: Mobile/web interface of the nursing care plan. 
study to assess the use of MW application by student nurses. In addition to this, the scales of Individual Innovativeness and Digital Literacy were also used.

\section{a. Assessment questionnaire for the use of mobile/ web based nursing care plan}

Students were given a Likert-type questionnaire with ten categories including the following headings: Difficulty, Complexity, User Friendliness, Time Management, Communication with the Supervisor, Submission to the Supervisor, Getting Assistance and Support, Visuality and Design, Comprehensibility, User Conformity. Students evaluated the nursing care plan, which they filled in, according to the difficulty level on a 1-5 scale where 5 was named "the most difficult" and 1 "very easy".

\section{b. Individual innovativeness scale}

The original form of "Individual Innovativeness (II) Scales" was developed by Hurt, et al., to determine health professionals' level of innovativeness [6]. The scale consisting of 20 statements, was adopted into Turkish with validity and reliability by Kiliçer and Odabaşi (2010). The $\alpha$ reliability coefficient of the original scale answered on five scores Likert form was found 0.89 . The Cronbach $\alpha$ coefficient of the scale adopted to Turkish is 0.82 . The scale is assessed on a single dimension over all items, not on their sub-dimensions. 12 of the items of the scale are positive (items $1,2,3,5,8,9,11,12$, 14, 16, 18.and 19), 8 negatives (items 4, 6, 7, 10, 13, 15, 17 and 20). Individual Innovation score is calculated by adding 42 scores to the score obtained by subtracting total scores from positive items from the total from negative items. The highest score obtained from the scale is 94; the lowest is 14 [7].

According to the scores calculated over the scale, individuals are classified according to their state of innovativeness. In this respect, if the calculated score is over 80 , the individual is assessed as "Innovators", 6980 "Early Adopters", 57-68 "Early Majority", 46-56 "Late Majority", below 46 "Laggards" [7].

According to the reliability analysis results obtained from the answers given by the participants in our study, the Cronbach Alpha reliability coefficient $\alpha=0.868$ was calculated for the Individual Innovation scale.

\section{c. The digital literacy scale (DLS)}

The digital literacy scale [8] includes 17 items and 4 factors (attitude, technical, cognitive and social). The original form of the scale was translated into Turkish language. The scale which does not have reverse items, is a Likert scale (five-point) ranging from "Strongly Agree (5)" to "Strongly Disagree (1)" [9].

According to the reliability analysis results obtained from the answers given by the participants in our study, the Cronbach Alpha reliability coefficient $\alpha=0.894$ was calculated for the digital literacy scale.

\section{Data Analysis}

The analysis of the data was performed using SPSS 22.0 through Kolmogorov-Smirnov test for univariate normality test. Spearman correlation analysis was used to find relations among variables after determining that no normality assumptions were to be taken into consideration.

A path analysis was performed on AMOS 21.0 by using separate models for the variables listed as the categories of the mobile/web application of the nursing care plan under the headings of 'difficulty', 'complexity', 'user friendliness', 'time management', 'communication with the supervisor', 'submission to the supervisor', 'getting assistance and support', 'visuality and design', 'comprehensibility' and 'user conformity'. Obtained data were assessed at 5\% significance level and 95\% confidence level.

\section{Ethical Considerations}

Official permission was obtained from the Surgical Chair of Health Research and Training Hospital of Trakya University on 17.11.2017 (no: 79056779-903.99). After the aim of the research was disclosed, students were asked to give their written informed consent.

\section{Results}

Of the participants, $69.5 \%$ were female, $30.5 \%$ were male, $39 \%$ were in the first class, and $97.5 \%$ were between 18-24 (Table 1).

According to the Relationship Matrix (Table 1), there is both negative and positive relationship between individual innovation and digital literacy and the assessment categories of the MW application (Spearman correlation) (Table 2).

While there is a positive and strong relationship ( $r$ $=0.72 ; p<0.01$ ) between "difficulty" and "complexity" variables of the MW application, there is a positive and weak relationship $(r=0.26 ; p<0.01)$ for "time management". There is a negative and weak relationship for individual innovation score $(r=-0.17 ; p<0.05)$.

Table 1: Students identifying characteristics.

\begin{tabular}{|l|l|l|}
\hline \multicolumn{2}{|l|}{} & n \\
\hline Sex & 139 & 69.5 \\
\hline Female & 61 & 30.5 \\
\hline Male & \multicolumn{2}{|l|}{} \\
\hline Class & 78 & 39 \\
\hline 1 & 69 & 34.5 \\
\hline 2 & 53 & 26.5 \\
\hline 3 & 195 & \\
\hline Age & \multicolumn{2}{|l|}{} \\
\hline $18-20$ & 5 & 97.5 \\
\hline $20-24$ & & 2.5 \\
\hline
\end{tabular}


Table 2: Correlations among variables.

\begin{tabular}{|c|c|c|c|c|c|c|c|c|c|c|c|c|}
\hline Variable & 1 & 2 & 3 & 4 & 5 & 6 & 7 & 8 & 9 & 10 & 11 & 12 \\
\hline Difficulty & 1 & & & & & & & & & & & \\
\hline Complexity & $0.73^{* *}$ & 1 & & & & & & & & & & \\
\hline User Friendliness & 0.08 & -0.05 & 1 & & & & & & & & & \\
\hline Time Management & $0.26^{* *}$ & 0.15 & $0.33^{* *}$ & 1 & & & & & & & & \\
\hline $\begin{array}{l}\text { Communication } \\
\text { with the } \\
\text { Supervisor }\end{array}$ & 0.11 & 0.00 & $0.56^{* *}$ & $0.44^{* *}$ & 1 & & & & & & & \\
\hline $\begin{array}{l}\text { Submission to the } \\
\text { Supervisor }\end{array}$ & 0.14 & 0.05 & $0.39^{* *}$ & $0.56^{* *}$ & $0.58^{* *}$ & 1 & & & & & & \\
\hline $\begin{array}{l}\text { Getting } \\
\text { Assistance and } \\
\text { Support }\end{array}$ & 0.05 & -0.14 & $0.46^{* *}$ & $0.42^{* *}$ & $0.64^{* *}$ & $0.49^{* *}$ & 1 & & & & & \\
\hline $\begin{array}{l}\text { Visuality and } \\
\text { Design }\end{array}$ & -0.02 & -0.02 & $0.46^{* *}$ & $0.40^{* *}$ & $0.45^{* *}$ & $0.47^{* *}$ & $0.61^{* *}$ & 1 & & & & \\
\hline Comprehensibility & -0.06 & $0.21^{* *}$ & $0.57^{* *}$ & $0.33^{* *}$ & $0.53^{* *}$ & $0.49^{* *}$ & $0.58^{* *}$ & $0.64^{* *}$ & 1 & & & \\
\hline User Conformity & 0.04 & -0.07 & $0.51^{\star *}$ & $0.53^{* *}$ & $0.50^{\star *}$ & $0.56^{* *}$ & $0.56^{* *}$ & $0.67^{\star *}$ & $0.70^{\star *}$ & 1 & & \\
\hline $\begin{array}{l}\text { Individual } \\
\text { Innovation Score }\end{array}$ & -0.04 & -0.02 & 0.10 & $0.21^{* *}$ & 0.03 & 0.12 & 0.13 & $0.24^{* *}$ & $0.24^{* *}$ & $0.15^{*}$ & 1 & \\
\hline Digital Literacy & $-0.17^{*}$ & $-0.17^{\star}$ & 0.10 & 0.11 & 0.04 & 0.10 & $0.19^{*}$ & $0.25^{\star *}$ & $0.22^{\star \star}$ & $0.17^{\star}$ & $0.34^{* *}$ & 1 \\
\hline Average & 3.27 & 3.25 & 2.97 & 3.29 & 3.03 & 3.35 & 3.00 & 3.02 & 3.10 & 3.11 & 62.66 & 3.54 \\
\hline $\begin{array}{l}\text { Standard } \\
\text { Deviation }\end{array}$ & 1.31 & 1.34 & 1.34 & 1.27 & 1.34 & 1.46 & 1.39 & 1.39 & 1.34 & 1.27 & 10.00 & 0.81 \\
\hline
\end{tabular}

There is a negative and weak relationship $(r=-0.21 ; p$ $<0.01$ ) between "complexity" and "comprehensibility" variables of the MW application and "digital literacy" ( $r$ $=-0.17 ; p<0.05$ ).

There are positive but not very strong relationships between "user friendliness" and "time management" $r$ $=0.33 ; p<0.0)$, "communication with the supervisor" $(r=0.56 ; p<0.01)$, "submission to the supervisor" ( $r$ $=0.39 ; p<0.01)$, "getting assistance and support" $(r$ $=0.46 ; p<0.01)$, "visuality and support" $(r=0.46 ; p$ $<0.01)$, "comprehensibility" ( $r=0.33 ; p<0.01)$, "user friendliness" ( $r=0.53 ; p<0.01)$.

There are positive relationships between "time management" and "communication with the supervisor" ( $r=0.44 ; p<0.01)$, "submission to the supervisor" ( $r=0.56 ; p<0.01)$, "getting assistance and support" $(r=0.42 ; p<0.01)$, "visuality and design" $(r=$ $0.40 ; p<0.01)$, "comprehensibility" $(r=0.33 ; p<0.01)$, "user conformity" $(r=0.53 ; p<0.01)$ and "individual innovation score" ( $r=0.21 ; p<0.01)$.

There are positive and strong relationships between "communication with the supervisor" and "submission to the supervisor" $(r=0.58 ; p<0.01)$, "getting assistance and support" $(r=0.64 ; p<0.01)$, "visuality and design" $(r=0.45 ; p<0.01)$, "comprehensibility" $(r=0.53 ; p<$ $0.01)$ and "user conformity" $(r=0.50 ; p<0.01)$.

There are positive and meaningful relationships between "submission to the supervisor" and "getting assistance and support" ( $r=0.49 ; p<0.01)$, "visuality and design" ( $r=0.47 ; p<0.01)$, "comprehensibility" ( $r$
$=0.49 ; p<0.01)$ and "user friendliness" $(r=0.56 ; p<$ $0.01)$.

There are positive and moderate relationships between "getting assistance and support" and "visuality and design" ( $r=0.61 ; p<0.01)$, "comprehensibility" ( $r$ $=0.58 ; p<0.01)$, "user conformity" $(r=0.56 ; p<0.01)$. However, there is a positive and weak relationship for "digital literacy" ( $r=0.19 ; p<0.05)$.

There are positive and very strong relationships between "visuality and design" and "comprehensibility" $(r=0.64 ; p<0.01)$ and "user conformity" $(r=0.67 ; p<$ 0.01 . On the other hand, there are positive and weak relationships between "individual innovation score" of "visuality and design" category $(r=0.24 ; p<0.01)$ and "digital literacy" ( $r=0.22 ; p<0.01)$.

There is a positive and strong relationship between "comprehensibility" and "user conformity" ( $r=0.70 ; p$ $<0.01$ ), but there is a positive and weak relationship between "individual innovation score" $(r=0.24 ; p<$ $0.01)$ and "digital literacy" ( $r=0.22 ; p<0.01)$.

There are positive but weak relationships between "user conformity" and "individual innovation score" $(r=0.15 ; p<0.05)$ and "digital literacy" $(r=0.17 ; p<$ $0.05)$. On the other hand, there is a positive and weak relationship between "individual innovation score" and "digital literacy" ( $r=0.34 ; p<0.01)$.

It can be stated that the higher "individual innovation score" is, the less the perception of "difficulty" in the assessment of the MW application. Similarly, it is 
understood that students with strong digital literacy perceive the MW application as being less complicated. Students who think the application is difficult to use also think that it is considerably complicated.

Students who regard the MW application as user friendly also report positive perceptions about the categories of "time management", "communication with the supervisor", "submission to the supervisor", "getting assistance and support", "visuality and design", "comprehensibility" and "user conformity".

Concepts in the theoretical model are described as structures, latent variables, or factors that are considered to exist in social sciences due to their unmeasurable structures theoretically but have no measurement units and can be measured through some signifiers. Jöreskog and Sörbom stated that structural equation modelling emphasizes facts in studies to examine uncertain causeeffect relationships and various causality effects [10]. Werner and Schermelleh-Engel developed the structural model that consists of the links among latent variables and the measurement model, which is considered to be linked to the variables observed by latent variables. These models help better understand the structural relationships within the theory [11].

About the relationships among variables, models constructed according to the aim of the study were evaluated through structural equation modelling and path analysis.

Through using structural equation modelling $[10,11]$ this study primarily examined the relationships among variables, after that, it analyzed the interaction among variables.

The theoretical model, which was constructed with the aim of the study and were evaluated through structural equation modeling and path analysis can be seen in Figure 1. Results in Table 3 were reached by testing 10 models that were separately constructed for assessment categories related to the $\mathrm{MW}$ application (Figure 2).

Table 3: Path analysis results.

\begin{tabular}{|c|c|c|c|c|c|}
\hline Model & B & $\beta$ & S.E. & C.R. & $\mathbf{P}$ \\
\hline \multicolumn{6}{|c|}{ Individual Innovation Score - > Digital Literacy - > Comprehensibility } \\
\hline Individual Innovation Score - > Digital Literacy & 0.035 & 0.434 & 0.007 & 5.123 & 0.000 \\
\hline Digital Literacy - > Comprehensibility & 0.476 & 0.283 & 0.140 & 3.404 & 0.000 \\
\hline \multicolumn{6}{|c|}{ Individual Innovation Score - > Digital Literacy - > Complexity } \\
\hline Individual Innovation Score - > Digital Literacy & 0.034 & 0.428 & 0.007 & 5.042 & 0.000 \\
\hline Digital Literacy - > Complexity & -0.349 & -0.205 & 0.140 & -2.491 & 0.013 \\
\hline \multicolumn{6}{|c|}{ Individual Innovation Score - > Digital Literacy - > User Conformity } \\
\hline Individual Innovation Score - > Digital Literacy & 0.034 & 0.430 & 0.007 & 5.065 & 0.000 \\
\hline Digital Literacy - > User Conformity & 0.405 & 0.252 & 0.133 & 3.038 & 0.002 \\
\hline \multicolumn{6}{|c|}{ Individual Innovation Score - > Digital Literacy - > Visuality and Design } \\
\hline Individual Innovation Score - > Digital Literacy & 0.034 & 0.433 & 0.007 & 5.101 & 0.000 \\
\hline Digital Literacy - > Visuality and Design & 0.607 & 0.346 & 0.147 & 4.126 & 0.000 \\
\hline \multicolumn{6}{|c|}{ Individual Innovation Score -> Digital Literacy - > Difficulty } \\
\hline Individual Innovation Score - > Digital Literacy & 0.034 & 0.429 & 0.007 & 5.061 & 0.000 \\
\hline Digital Literacy - > Difficulty & -0.292 & -0.176 & 0.137 & -2.137 & 0.033 \\
\hline \multicolumn{6}{|c|}{ Individual Innovation Score - > Digital Literacy - > Getting Assistance and Support } \\
\hline Individual Innovation Score - > Digital Literacy & 0.034 & 0.428 & 0.007 & 5.069 & 0.000 \\
\hline Digital Literacy - > Getting Assistance and Support & 0.425 & 0.242 & 0.146 & 2.920 & 0.004 \\
\hline \multicolumn{6}{|c|}{ Individual Innovation Score - > Digital Literacy - > Time Management } \\
\hline Individual Innovation Score - > Digital Literacy & 0.034 & 0.433 & 0.007 & 5.095 & 0.000 \\
\hline Digital Literacy - > Time Management & 0.282 & 0.176 & 0.132 & 2.138 & 0.033 \\
\hline
\end{tabular}

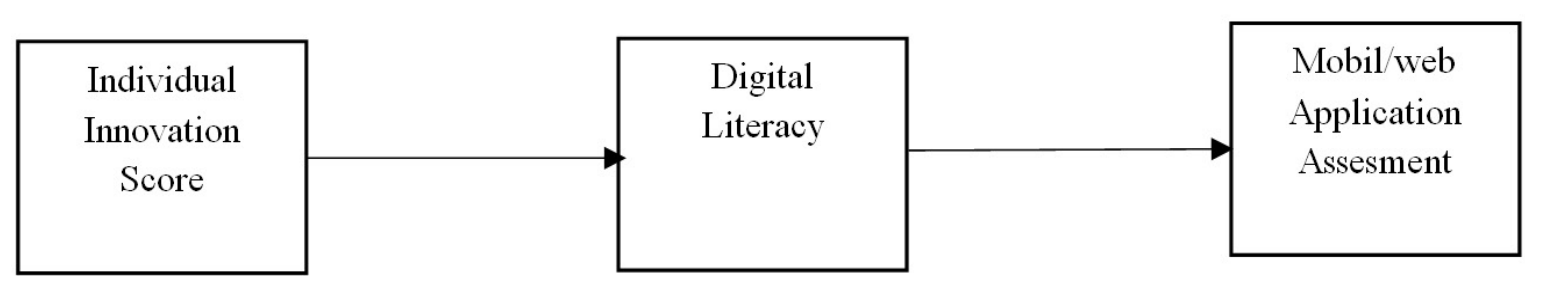

Figure 2: Conceptual model. 
Among ten different models, the path between "digital literacy" and assessment categories was found insignificant for models related to the categories of "Communication with the Supervisor" (CR $=0.829, p>$ $0.05)$, "Submission to the Supervisor" (CR $=1.056, p>$ 0.05 ) and "User Friendliness" (CR $=1.914, p>0.5$ ) (Table $3)$.

The causality relationship between individual innovation score, digital literacy and "Comprehensibility" of the MW application is stated in the first model analyzed through structural equation model. According to standardized regression coefficients, it is seen that path coefficients between individual innovation score and digital literacy $(\beta=0.434, p<0.05)$ and "digital literacy" and "Comprehensibility" $(\beta=0.283, p<0.05)$ are meaningful. Harmony goodness values (HGV) show that the model is in good conformity and confirms structural equation $\left(\chi^{2} / d f=1.376, \mathrm{RMSEA}=0.047, \mathrm{CFI}=\right.$ $0.981, \mathrm{GFI}=0.944)$. According to the analysis results, as the level of individual innovation increases positively, so does students' level of digital literacy and they find MW application more comprehensible.

The second model is concerned with "Complexity". Path coefficients between individual innovation score and "digital literacy" ( $\beta=0.428, p<0.05)$ and "digital literacy" and "Comprehensibility" ( $\beta=-0.205, p<0.05)$ are meaningful. HGV display that the model is in good conformity and confirms structural equation $\left(\chi^{2} / \mathrm{df}=\right.$ 1.321, $\mathrm{RMSEA}=0.044, \mathrm{CFI}=0.984, \mathrm{GFI}=0.948)$. As the level of individual innovation score increases positively, so does the level of students' digital literacy and they find MW application less complex.

In the third model regarding the "User Conformity" it is observed that path coefficients between individual innovation and "digital literacy" $(\beta=0.430, p<0.05)$ and "digital literacy" and "User Conformity" $(\beta=0.252, p<$ $0.05)$ are meaningful. HGV display that the model is in good conformity and confirms structural equation $\left(\chi^{2}\right)$ $\mathrm{df}=1.435, \mathrm{RMSEA}=0.051, \mathrm{CFI}=0.979, \mathrm{GFI}=0.943)$. As the level of individual innovation score increases positively, so does the level of students' digital literacy and they find MW application less complex in terms of "User Conformity".

In the fourth model for the "Visuality and Design" it is seen that path coefficients between individual innovation score and "digital literacy" $(\beta=0.433, p<$ $0.05)$ and "digital literacy" and "User Conformity" $(\beta=$ $0.346, p<0.05$ ) are meaningful. HGV display that the model is in good conformity and confirms structural equation $\left(\chi^{2} / \mathrm{df}=1.264\right.$, RMSEA $=0.040, \mathrm{CFI}=0.987, \mathrm{GFI}$ $=0.950)$. As the level of individual innovation increases positively, so does the level of students' digital literacy and they find MW application positive in terms of "Visuality and Design".

In the fifth model covering the "Getting Assistance and Support" category, path coefficients between individual innovation score and "digital literacy" ( $\beta$ $=0.430, p<0.05)$ and "digital literacy" and "Getting Assistance and Support" $(\beta=0.242, p<0.05)$ are meaningful. HGV display that the model is in good conformity and confirms structural equation $\left(\chi^{2} / \mathrm{df}=\right.$ 1.264, $\mathrm{RMSEA}=0.040, \mathrm{CFI}=0.987, \mathrm{GFI}=0.950)$. As the level of individual innovation score increases positively, so does the level of students' digital literacy and they find MW application positive in terms of "Getting Assistance and Support".

In the sixth model including the "Time Management", path coefficients between individual innovation score and "digital literacy" $(\beta=0.433, p<0.05)$ and "digital literacy" and "User Conformity" $(\beta=0.176, p<0.05)$ are meaningful. HGV display that the model is in good conformity and confirms structural equation $\left(\chi^{2}\right)$ $\mathrm{df}=1.507, \mathrm{RMSEA}=0.055, \mathrm{CFI}=0.975, \mathrm{GFI}=0.938)$. As the level of individual innovation score increases positively, so does the level of students' digital literacy and they find MW application positive in terms of "Time Management".

In the seventh model, the causality relationship between individual innovation score and "digital literacy" and the "Difficulty" category of the MW application is discussed. Path coefficients between individual innovation score and "digital literacy" ( $\beta$ $=0.429, p<0.05)$ and "digital literacy" and "User Conformity" ( $\beta=-0.176, p<0.05)$ are meaningful. HGV display that the model is in good conformity and confirms structural equation $\left(\chi^{2} / \mathrm{df}=1.300, \mathrm{RMSEA}=\right.$ $0.042, \mathrm{CFI}=0.985, \mathrm{GFI}=0.949$ ). As the level of individual innovation score increases positively, so does the level of students' digital literacy and their perception of the MW application in terms of "Difficulty" Students' was found low.

Statistical significance between the Digital Literacy scale and students' age, gender and class variables were found in the gender variable $(p<0.05)$. Accordingly, male students' level of Digital Literacy was higher than female students $(\bar{x}=38.73 \pm 7.93)$. Although there is no statistically significant difference, the Digital Literacy level of $4^{\text {th }}$-grade students were found to be higher compared to $2^{\text {nd }}$ and $3^{\text {rd }}$-grade students, and the Digital Literacy level of the students in the 20-24 age group was found to be higher than the students in the 18-20 age group.

No statistical significance was found between the individual innovativeness scale and the variables of students' age, gender, class $(p>0.05)$. In the analysis, it is seen that in line with the answers given by the students, they are in the "Early Majority" class with the general scale point average $(\bar{x}=62.17 \pm 9.09)$. This detected situation did not change in terms of age, gender and class variables. Male students compared to female students, $4^{\text {th }}$-grade students compared to 
Table 4: Comparison of students' socio-demographic characteristics and scale score averages.

\begin{tabular}{|c|c|c|c|c|}
\hline & \multicolumn{2}{|c|}{ Digital Literacy } & \multicolumn{2}{|c|}{ Individual Innovativenes } \\
\hline & Mean \pm SD & Min-Max & Mean \pm SD & Min-Max \\
\hline Total $(n=200)$ & $35.44 \pm 8.08$ & $10-50$ & $62.17 \pm 9.09$ & $45-92$ \\
\hline \multicolumn{5}{|l|}{ Sex } \\
\hline Male $(n=55)$ & $38.73 \pm 7.93$ & $10-50$ & $62.50 \pm 9.84$ & $45-90$ \\
\hline Female $(n=145)$ & $34.20 \pm 7.82$ & $10-50$ & $62.05 \pm 8.84$ & $46-92$ \\
\hline Statistical Evaluation/MWU & \multicolumn{2}{|c|}{$1722.00 / \mathrm{P}<\mathbf{0 . 0 0 5}$} & \multicolumn{2}{|c|}{$2797.50 / P>0.005$} \\
\hline \multicolumn{5}{|l|}{ Class } \\
\hline $2(n=102)$ & $34.62 \pm 8.66$ & $10-50$ & $61.77 \pm 8.72$ & $46-92$ \\
\hline $3(n=53)$ & $35.69 \pm 7.29$ & $10-50$ & $61.33 \pm 9.67$ & $45-90$ \\
\hline $4(n=44)$ & $36.11 \pm 7.93$ & $13-50$ & $63.80 \pm 8.95$ & $45-87$ \\
\hline Statistical Evaluation/KW & \multicolumn{2}{|c|}{$1.075 / P>0.005$} & \multicolumn{2}{|c|}{$3.650 / P>0.005$} \\
\hline \multicolumn{5}{|l|}{ Age } \\
\hline $18-20(n=195)$ & $35.41 \pm 8.16$ & $10-50$ & $62.21 \pm 9.04$ & $45-92$ \\
\hline $20-24(n=5)$ & $36.40 \pm 5.77$ & $27-42$ & $61.00 \pm 11.95$ & $50-74$ \\
\hline Statistical Evaluation/MWU & \multicolumn{2}{|c|}{$374.000 / \mathrm{P}>0.005$} & \multicolumn{2}{|c|}{$346.00 / P>0.005$} \\
\hline
\end{tabular}

\section{*SD: Standard Deviation}

$2^{\text {nd }}$ and $3^{\text {rd }}$-year students, $18-20$ age group students compared to 20-24 age group students in terms of individual innovativeness were found to be more "Early Majority" (Table 4).

\section{Discussion}

It is observed that as students' individual innovation level increases, their digital literacy level considerably increases, too. Improvement in digital literacy helps students to evaluate the MW application as being easier and less complicated.

It was reported that learning leans towards mobile settings where individuals' demands and needs are foregrounded with more sociable and synchronous settings [12-14]. In a study on environmental education, students learning performances through different methods and concluded that use of tablets, PDAs, PCs and smartphones increased learning performance [15]. The fact there is no common language and terminology in the nursing profession, that the subjects of computer and ITs are ranked inadequately in the curriculum, that there are different levels of nursing education and nurses with different levels of qualifications are given the same roles and responsibilities lead to a faint development in the use of ITs in society $[16,17]$. In a study, it is stated that $65.1 \%$ of the participants believed that in the issue of nursing practices, use of technology facilitates nursing practices. If nurses are not satisfied with the software, it has a negative effect on patient safety and care. The nurses are happier with the one based on mobile technology compared to pen and paper system [18]. It was found in our study that students with higher individual innovation score and stronger digital literacy perceive MW application as being less complicated. The fact that students reporting $\mathrm{MW}$ application developed for nursing care plan is complicated may arise from the ground they have the constraints of the process of adapting a new method that is quite different from the conventional one and from the digital divide caused by the changing levels of digital literacy of the students coming from different cities of the country. Our study indicated that for the effect of Individual Effectiveness, it can be stated that as the level of digital literacy increases, there is a positive causality effect on students 'assessments that the MW application is found productive in terms of "Comprehensibility", "User Conformity", "Visuality and Design", "Getting Assistance and Support" and "Time Management". It is also realized that the perceptions of time management, communication with the supervisor, submission to the supervisor, getting assistance and support, visuality and design are positive. A study regarding the application of the nursing care plans through hospital information management system show that compared to pen and paper nursing care plans, nurses spent less time when they prepare it on an automated system and it was much easier for them to do so. In addition, nurses with more expertise in their field developed a more positive attitude compared to the ones with less expertise [18]. In our study, it is seen that students whose level of individual innovation and digital literacy increase positively find the MW application developed for preparing nursing care plans more advantageous in terms of time management.

Hsu, et al. showed through mobile applications, advantage of innovation, usability, conformity, and observability are the most important factors in the acceptance and adoption process of innovation. It was also put forward that adoption of the tendency of innovativeness towards technology is one of the biggest factors in the effective use of technology [19]. 
Individual characteristics (namely individual innovativeness) influence individuals' intentions of the adoption and maintenance of innovation in earlier and contextual factors (namely social effect) do so in later stages [20].

The literature states that the use, efficiency, and level of digitalization of information and communication technologies decrease with age [21]. In our study, it was found that it increased with age. It is thought that this situation is due to the decrease in the level of evaluating the mobile/web application as difficult and complex as the average age of the student's increases. Again, while studies in the literature show that digital literacy levels are higher in men than in women in terms of gender, some studies do not differ by gender [22,23]. In this study, following the literature, the Digital Literacy levels of male students were found to be higher than female students.

While studies in the literature found a significant difference between students' individual innovativeness characteristics and gender [24], some studies did not find any difference in terms of gender [25]. Consistent with the literature, we found no significant difference in gender in this study, but similar findings were found between age and class variables. It is thought that the student's individual characteristics may cause this situation.

\section{Conclusion}

It can be concluded that nurse students found that MW application was more advantageous in transferring their theoretical knowledge into their clinical practices and more contributory to the science of nursing education. The increase in digital literacy through the effect of individual innovation has a positive causality effect on students' evaluations that the MW application is productive in terms of comprehensibility, userfriendliness, visuality and design, getting assistance and support and time management.

The improvement in the level of digital literacy allows students to assess the MW application as less complicated and easier. MW applications are an indispensable part of students' lives and it is an undeniable fact that using that instrument provides numerous advantages to students by motivating them to learn through new technologies and methods. As a well-constructed nursing education will contribute a lot to the progress of the nursing profession, in addition to the traditional one, contemporary education plans that are compatible with the digital age need to be initiated immediately.

In facilitating the adoption of new technologies, it is quite essential to take into consideration students' level of individual innovation and digital literacy. MW technologies provide many advantages in that they facilitate access to nursing care instruments that support better clinical decision-making processes and the improvement of patient records. Improving more our applied MW source developed for nursing care plans and integrating into nursing activities may provide students to acquire better educational skills for the quality of care.

\section{Authors' Contributions}

Conception: SE, TD, EÖ. Design: Supervision: SE, EÖ. Funding: SE, TD, EÖ. Literature review: SE, EÖ. Data collection: SE. Data analysis and interpretation: TD, EÖ. Drafting of the article: SE, EÖ, TD.

\section{Conflicts of Interest}

The authors have not conflicts of declare of interest.

\section{Funding}

None.

\section{Acknowledgments}

We would like to thank the following students for their participation to the research and also express our deepest appreciation for their hard work. Without them, this study could not have been completed. Names of the Research Students (in alphabetical order): Ahmet Kiziltan, Arzu Kaba, Ayşegül Atilla, Buse Kaya, Fatih T. Altintaş, Furkan A. Konur, Serkan Duman, Yavuzhan Durmaz. We would like to thank the students for participating in this study.

\section{Supplementary Materials}

None.

\section{Declarations of Interest}

None.

\section{References}

1. Haggerty E (2017) Healthcare and digital transformation. Network Security 2017: 7-11.

2. Raman J (2015) Mobile technology in nursing education: Where do we go from here? A review of the literature. Nurse Educ Today 35: 663-672.

3. Dil S, Uzun M, Aykanat B (2012) Innovation in nursing education. Journal of Human Sciences 9: 1217-1228.

4. Kanter RM (2006) İnnovation: The classic traps. Harvard Business Review 84: 72-83.

5. Şahin G, Başak T (2017) Mobile learning in nursing "m-learning" (Hemşirelikte mobil öğrenme "m-öğrenme"). International Journal of Human Sciences 14: 4480-4491.

6. Hurt HT, Joseph K, Cook CD (1977) Scales for the measurement of innovativeness. Human Communication Research 4: 58-65.

7. Kiliçer K, Odabaşi HF (2010) Individual Innovativeness Scale (Is): The study of adaptation to Turkish, validity and reliability (Bireyselyenilikçilikölçeği (BYÖ): Türkçeyeuyarlama, geçerlikvegüvenirlikçalişmasi). $H$. U. Journal of Education 38: 150-164. 
8. Ng W (2012) Can we teach digital natives' digital literacy? Computers \& Education 59: 1065-1078.

9. Burcin Hamutoğlu N, Canan Güngören Ö, Kaya Uyanik G, Gür Erdoğan D (2017) Adapting digital literacy scale into Turkish. Ege Journal of Education 18: 408-429.

10. Jöreskog KG, Sörbom D (1982) Recent developments in structural equation modeling. J Marketing Res 19: 404-416.

11. Werner C, Schermelleh-Engel K (2009) Structural equation modeling: Advantages, challenges, and problems. Goethe University, Frankfurt, 1-4.

12. Clements JA, Boyle R (2018) Compulsive technology use: Compulsive use of mobile applications. Computers in Human Behavior 87: 34-48.

13. Özcan S, Gökçearslan Ş, Solmaz E (2016) Investigation into attitudes of pre service teachers towards e-learning with respect to their individual innovativeness levels. Journal of Educational and Instructional Studies in the World 6: 31-38.

14. Zhu C, Engels N (2014) Organizational culture and instructional innovations in higher education: Perceptions and reactions of teachers and students. Educ Manag Adm Lead 42: 136-158.

15. Chang CS, Chen TS, Hsu WH (2011) The study on integrating WebQuest with mobile learning for environmental education. Computers \& Education 57: 1228-1239.

16. Mennenga HA (2016) Nursing student perceptions of digital textbooks: A pilot study. Nurs Educ Perspect 37: 107-109.

17. Top M, Gider O (2012) Nurses' views on electronic medical records (EMR) in Turkey: An analysis according to use, quality and user satisfaction. J Med Syst 36: 1979-1988.
18. Stevenson JE, Nilsson GC, Petersson GI, Johansson PE (2010) Nurses' experience of using electronic patient records in everyday practice in acute/inpatient ward settings: A literature review. Health Informatics J 16: 63-72.

19. Hsu CL, Lu HP, Hsu HH (2007) Adoption of the mobile Internet: An empirical study of multimedia message service (MMS). Omega 35: 715-726.

20. Sun $Y$, Jeyaraj A (2013) Information technology adoption and continuance: A longitudinal study of individuals' behavioral intentions. Information \& Management 50: 457465.

21. Marsh J, Hannon P, Lewis M, Ritchie L (2017) Young children's initiation into family literacy practices in the digital age. Journal of Early Childhood Research 15: 47-60.

22. Özerbaş MA, Kuralbayeva A (2018) A review of digital literacy levels of future primary-school and secondaryschool teachers in Turkey and Kazakhstan. MSKU Journal of Education 5: 16-25.

23. Özden M (2018) Digital literacy perceptions of the students in the department of computer technologies teaching and Turkish language teaching. International Journal of Progressive Education 14: 26-36.

24. Ertuğ N, Kaya H (2017) Investigating the individual innovativeness profiles and barriers to innovativeness in undergraduate nursing students. Journal of Education and Research in Nursing 14: 192-197.

25. Korucu AT, Olpak YZ (2015) Examination of teacher candidates individual innovativeness properties from the different variables. Educational Technology Theory and Practice 5: 111-127. 